\title{
PRODUÇÃO DE CEBOLINHA CULTIVADA SOB TELAS DE SOMBREAMENTO EM CÁCERES-MT
}

Altacis Junior de Oliveira1, Daniela Soares Alves Caldeira ${ }^{2}$, Andressa Alves Cabreira dos Santos $^{3}$, Gustavo Ferreira da Silva ${ }^{4}$, Marcella Karoline Cardoso Vilarinho ${ }^{5}$

\footnotetext{
${ }^{1}$ Mestrando no Programa de Pós Graduação em Genética e Melhoramento de Plantas da Universidade do Estado de Mato Grosso (UNEMAT), Alta Floresta/MT, Brasil.

${ }^{2}$ Professora Doutora do curso de Agronomia da UNEMAT, Cáceres/MT, Brasil.

E-mail: danielacaldeira@unemat.br.

${ }^{3}$ Bacharel em Agronomia da UNEMAT, Cáceres/MT, Brasil.

${ }^{4}$ Mestrando no Programa de Pós Graduação em Agricultura da Faculdade de Ciências Agronômicas/UNESP, Botucatu/SP, Brasil.

${ }^{5}$ Professora Mestre do curso de Agronomia da UNEMAT, Cáceres/MT, Brasil.
}

\section{Recebido em: 06/04/2019 - Aprovado em: 10/06/2019 - Publicado em: 30/06/2019 DOI: 10.18677/EnciBio_2019A106}

\begin{abstract}
RESUMO
A cebolinha (Allium fistulosum L.) se destaca como um condimento utilizado na culinária para melhorar o sabor e a qualidade nutricional dos alimentos. É comumente produzida em canteiros a pleno sol, apesar da luz e da temperatura serem os fatores climáticos que mais afetam sua produção e limitam o cultivo. Nesse sentido, objetivou-se avaliar a produção de cebolinha cultivada sob diferentes telas de sombreamento e em pleno sol nas condições climáticas de Cáceres-MT. O delineamento experimental adotado foi em blocos casualizados, com 4 tratamentos (tela vermelha Chromatinet ${ }^{\circledR}$, tela sombrite preta, tela termo refletora, todas com $50 \%$ de sombreamento e a pleno sol) em 4 repetições contendo 10 plantas cada. $A$ avaliação de produção foi realizada 60 dias após o transplantio das mudas, utilizando-se 5 plantas por repetição onde foram determinados: altura do perfilho central, diâmetro do perfilho central, número de perfilhos, números de maços (com 12 perfilhos) e massa fresca e seca. As cebolinhas cultivadas sob tela vermelha e termo refletora apresentaram maior diâmetro do perfilho central, maior massa fresca e seca que as plantas cultivadas sob tela preta e a pleno sol. A altura do perfilho central mostrou-se superior sob tela vermelha e não se observou interferência dos ambientes estudados para as variáveis número de perfilhos e número de maços por planta. Desta forma, indica-se o uso de tela vermelha ou termo refletora para produção de cebolinha na região Cáceres-MT.
\end{abstract}

PALAVRAS-CHAVE: Allium fistulosum L., ambiente protegido, telas coloridas.

\section{PRODUCTION OF CHIVE ONION CULTIVATED UNDER SHADING SCREEN IN CÁCERES / MT}

\section{ABSTRACT}

Chives (Allium fistulosum L.) stands out as a condiment used in cooking to improve the taste and nutritional quality of food. It is commonly produced in flower beds in full 
sun, although light and temperature are the climatic factors that most affect its production and limit cultivation. In this sense, the objective of this work was to evaluate the production of chives cultivated under different shading screens and in full sun under the climatic conditions of Cáceres-MT. The experimental design was a completely randomized block design with four treatments (Chromatinet® red screen, black shade screen, thermo reflective screen, all with $50 \%$ shading and full sun) in 4 repetitions containing 10 plants each. The production evaluation was performed 60 days after the transplanting of the seedlings, using 5 plants per repetitions in wich were determined: central tiller height, central tiller diameter, number of tillers, number of bundles (with 12 tiller) and fresh mass and dried. The onions cultivated under red and thermo-reflector screen presented a larger diameter of the central tiller, bigger fresh and dry mass than the plants grown under black screen and in full sun. The height of the central tiller showed to be superior under red screen and no interference of the studied environments was observed for the number of tillers and number of bundles per plant. In this way, the use of red or thermo-reflector screen for chives production in the Cáceres-MT region is indicated.

KEYWORDS: Allium fistulosum L., protected environment, colored screens.

\section{INTRODUÇÃO}

As hortaliças são vegetais de ciclo rápido e que são consumidas in natura em larga escala devido ao seu valor nutricional e às propriedades associadas à prevenção de algumas doenças (ALVES et al., 2010).

Dentre as hortaliças mais consumidas e cultivadas no Brasil, destaca-se a cebolinha comum (Allium fistulosum L.), originária da Sibéria, pertencente à família das Aliáceas e comumente utilizada como condimento para melhorar o sabor e a qualidade nutritiva dos alimentos (MAKISHIMA, 1993; FREDDO et al., 2014).

As plantas dessa espécie são consideradas perenes, propagadas via sementes ou vegetativamente, e caracterizam-se pelo intenso perfilhamento, formando touceiras. Produzem pequenos bulbos cônicos e apresentam folhas verdes escuras e fistulosas, com altura em torno de 300 a 500 mm (FILGUEIRA, 2013).

A cebolinha é produzida em canteiros a pleno sol e nesse sistema, as plantas ficam expostas a fatores bióticos e abióticos, que podem causar reduções na quantidade e na qualidade do produto final. É considerada uma cultura tolerante às variações de temperatura, suportando frios prolongados e certa resistência ao calor. Apresenta melhor desenvolvimento na faixa de temperatura de $8^{\circ} \mathrm{C}$ a $22^{\circ} \mathrm{C}$ e $\mathrm{o}$ perfilhamento é maior nos plantios de fevereiro a julho nas regiões produtoras do Brasil (MAKISHIMA, 1993; FILGUEIRA, 2013).

A produção agropecuária em países de clima tropical como o Brasil torna-se desafiadora em decorrência das temperaturas elevadas que podem limitar a produção de espécies hortícolas, fazendo com que produtores optem pelo uso de ambientes protegidos (HIRATA; HIRATA, 2015; COSTA et al., 2017).

Dessa forma, o cultivo em ambiente protegido com a utilização de telas de sombreamento pode minimizar os efeitos da temperatura sobre a planta, permitindo a realização de cultivos em épocas que normalmente não seriam escolhidas para a produção em pleno sol (SANTOS et. al., 2010).

As telas de sombreamento são amplamente utilizadas no sistema produtivo das hortaliças folhosas como alface e rúcula (QUEIROZ et al., 2014; HIRATA; HIRATA, 2015), todavia são desconhecidos os efeitos dessa tecnologia na cultura da cebolinha (HIRATA et al., 2017). 
A utilização de telas possibilita certo controle das condições edafoclimáticas como: temperatura, umidade do ar, radiação, solo, vento e composição atmosférica, favorecendo espécies que necessitam de menor fluxo de energia radiante. Santos et al.(2010) estudando as variações de luminosidade, temperatura do ar e do solo em ambientes com telas de sombreamento concluíram a eficiência na redução desses parâmetros, demonstrando ser viável o uso destas telas para cultivo em condições tropicais. Ao avaliarem a temperatura do ar em ambientes de cultivo protegido em Cáceres-MT, observaram que os telados proporcionaram uma redução de temperatura de até $6 \%$ em comparação ao pleno sol.

No entanto, o uso dessas telas visando diminuir temperatura e irradiância elevada, pode apresentar o inconveniente de reduzir o fluxo de luz a níveis inadequados, promovendo prolongamento do ciclo, estiolamento das plantas e redução da produtividade (GINEGAR POLYSACK, 2017).

As malhas coloridas, também conhecidas como telas fotosseletivas, podem ser encontradas em várias colorações (azul, vermelho, amarelo, verde e cinza) com o objetivo de causar mudanças no espectro de radiação disponível para planta, proporcionando ajustes metabólicos no sistema fotossintético (SABINO et al., 2016)

As telas termorefletoras existentes no mercado estão sendo amplamente utilizadas na agricultura, além de promoverem sombreamento, possuem as características de serem metalizadas em alumínio em ambas as faces permitindo reflexão de parte da energia solar. Desta forma é possível obter menores temperaturas no verão e maiores no inverno (COSTA et al., 2017).

Em regiões quentes como Cáceres-MT, onde a temperatura média anual entre 1971 a 2009 foi de $26,24^{\circ} \mathrm{C}$ e a máxima absoluta foi de $41,2^{\circ} \mathrm{C}$ (NEVES et al., 2011) deve-se ter critérios na escolha do ambiente protegido e cuidados na sua utilização, pois além das altas temperaturas a má utilização desses ambientes pode acarretar incremento de radiação infravermelha e calórica. A elevação na temperatura dentro do ambiente pode causar estresse térmico na planta e diversos danos, como a aceleração do metabolismo com incremento do processo respiratório e desnaturação proteica, podendo gerar depressão da fotossíntese (SANTOS et al.,2010).

As informações sobre cultivo de cebolinha ainda são escassas na literatura, apesar do uso crescente de ambientes protegidos para a produção de hortaliças (SILVA et al., 2015). Considerando-se o exposto, objetivou-se avaliar a produção de cebolinha sob diferentes telas de sombreamento em Cáceres/MT.

\section{MATERIAL E MÉTODOS}

$\mathrm{O}$ experimento foi conduzido na área experimental de Agronomia pertencente à UNEMAT, localizada no Município de Cáceres-MT (1604'33"S; 57³9'10", altitude $118 \mathrm{~m}$ ), no período de abril a junho de 2017 . A região apresenta clima tropical com temperatura máxima anual de $32,4^{\circ} \mathrm{C}$, mínima de $20,3^{\circ} \mathrm{C}$ e média compensada de $32,4^{\circ} \mathrm{C}$, podendo ocorrer temperaturas de $40^{\circ} \mathrm{C}$. A pluviosidade anual é de aproximadamente $1311,85 \mathrm{~mm}$, concentrando $45 \%$ nos meses de dezembro a fevereiro (NEVES et al., 2011). No período de cultivo foram observadas temperaturas máximas de até $28,7^{\circ} \mathrm{C}$ e mínimas de $20,0^{\circ} \mathrm{C}$ (INMET, 2017).

$\mathrm{O}$ delineamento experimental utilizado foi em blocos casualizados com quatro tratamentos, sendo: tela Chromatinet ${ }^{\circledR}$ vermelha (TCV), tela termo refletora (TTR), tela de sombreamento preta (TSP) todas com $50 \%$ de sombreamento e em pleno sol 
(PS), com quatro repetições contendo dez plantas por repetição, num total de 160 plantas.

O material propagado foi obtido através da doação de um produtor da região Cáceres-MT e inicialmente realizou-se limpeza, corte dos bulbos deixando-os com dez $\mathrm{cm}$ acima da base e corte das raízes deixando-as com três $\mathrm{cm}$, seguindo recomendação de Oliveira et al. (2012).

As mudas foram transplantadas em sacos de polietileno com capacidade para dois litros preenchidos com terra de subsolo e areia na proporção de 3:1. A adubação foi realizada usando-se cinco quilos de esterco bovino por $\mathrm{m}^{2}$ de substrato.

Após 30 dias do plantio foi realizada adubação foliar com Biofert na formulação 8-6-6 NPK +10 micronutrientes (magnésio, enxofre, boro, cloro, cobalto, cobre, ferro, manganês, molibdênio e zinco) na dose de dez $\mathrm{mL}$ por litro de água, pulverizando $250 \mathrm{ml}$ para cada ambiente de produção. A irrigação foi realizada diariamente, duas vezes ao dia, de forma manual utilizando regador.

A colheita foi realizada manualmente 60 dias após o transplantio e foram avaliadas cinco plantas de cada repetição, totalizando 20 plantas por tratamento, determinando-se altura do perfilho central $(\mathrm{cm}) \mathrm{com}$ uso de régua milimetrada; diâmetro do perfilho central $(\mathrm{mm})$ com auxílio de paquímetro; número de perfilhos e números de maços (com doze perfilhos) por meio de contagem direta. Para avaliação da massa fresca ( $\mathrm{g}$ ) e seca ( $\mathrm{g}$ ) o material foi pesado e posteriormente colocado para secagem em estufa de circulação forçada a $65^{\circ} \mathrm{C}$ até peso constante e então, pesado novamente.

Os dados obtidos foram submetidos à análise de variância pelo teste de $\mathrm{F}$ e as médias comparadas pelo teste de Tukey a $5 \%$ de probabilidade, utilizando-se o programa Assistat (SILVA; AZEVEDO, 2016).

\section{RESULTADOS E DISCUSSÃO}

Conforme observa-se na Tabela 1 , os diferentes ambientes testados influenciaram os parâmetros analisados, exceto para número de perfilhos e número de maços. Com relação à altura do perfilho central da cebolinha, a tela vermelha proporcionou elevação de $18,47 \%$ quando comparada aos demais tratamentos. Nesse sentido, Hirata et al. (2017) afirmaram que plantas cultivadas sob telas de sombreamento apresentam incremento em altura quando comparadas ao cultivo em pleno sol.

TABELA 1- Produção de cebolinha (Allium fistulosum L.) cultivada em diferentes ambientes em Cáceres - MT.

\begin{tabular}{lcccccc}
\hline Ambientes & Altura $(\mathrm{cm})$ & $\begin{array}{c}\text { Diâmetro } \\
(\mathrm{mm})\end{array}$ & $\begin{array}{c}\text { № de } \\
\text { perfilhos }\end{array}$ & $\begin{array}{c}\text { № de } \\
\text { maços }\end{array}$ & $\begin{array}{c}\text { Massa } \\
\text { fresca }(\mathrm{g})\end{array}$ & $\begin{array}{c}\text { Massa } \\
\text { seca }(\mathrm{g})\end{array}$ \\
\hline TCV & $26,53 \mathrm{a}$ & $7,57 \mathrm{a}$ & $33,25 \mathrm{a}$ & $2,82 \mathrm{a}$ & $40,57 \mathrm{a}$ & $3,57 \mathrm{a}$ \\
TTR & $23,25 \mathrm{~b}$ & $7,05 \mathrm{a}$ & $36,00 \mathrm{a}$ & $3,00 \mathrm{a}$ & $34,43 \mathrm{ab}$ & $3,46 \mathrm{a}$ \\
TSP & $21,64 \mathrm{~b}$ & $6,22 \mathrm{~b}$ & $36,50 \mathrm{a}$ & $3,04 \mathrm{a}$ & $26,17 \mathrm{bc}$ & $2,42 \mathrm{~b}$
\end{tabular}




\begin{tabular}{lllllll} 
PS & $20,00 \mathrm{~b}$ & $6,07 \mathrm{~b}$ & $29,00 \mathrm{a}$ & $2,42 \mathrm{a}$ & $23,62 \mathrm{c}$ & $2,19 \mathrm{~b}$ \\
\hline $\mathrm{CV}(\%)$ & 6,49 & 4,24 & 11,20 & 10,42 & 14,68 & 13,80 \\
\hline
\end{tabular}

*As médias seguidas pela mesma letra na coluna não diferem estatisticamente entre si, pelo Teste de Tukey ao nível de $5 \%$ de probabilidade.

${ }^{* *}$ Tela Chromatinet ${ }^{\circledR}$ vermelha $(T C V)$, tela termo refletora (TTR), tela de sombreamento preto (TSP) e Pleno Sol (PS).

A altura do perfilho central da cebolinha cultivada em pleno sol foi $24,61 \%$ inferior aos resultados encontrados quando esta foi cultivada sob tela vermelha. Luz et al. (2012) ao avaliarem o cultivo de salsa em diferentes níveis de sombreamento observaram que as plantas cultivadas em ambiente de pleno sol obtiveram a menor média de altura de plantas. Sugere-se que este fato possa ser explicado pelo excesso de luz que pode resultar em condição de estresse conhecida como fotoinibição, diminuindo a incorporação de biomassa pelas plantas (TAIZ; ZEIGER, 2013). Além de redução na fotossíntese, a altura pode ter sido prejudicada também por um aumento da taxa respiratória, diminuindo a fotossíntese líquida e, consequentemente, a produção e acúmulo de biomassa (SANTOS et al., 2010).

Desta forma, nota-se que a colheita em ambiente com tela vermelha pode ser realizada em menor tempo, quando comparada com o ambiente de cultivo em pleno sol, tendo em vista, que o ponto de colheita de cebolinha é indicado a partir de 20 cm de altura do perfilho central (MAKISHIMA, 1993).

O diâmetro do perfilho central, também foi influenciado pelos ambientes de produção sendo que a tela termo refletora e a tela vermelha foram superiores $(15,94 \%)$ aos demais ambientes testados. Esse comportamento pode ser devido ao fato da tela termo refletora promover boa ventilação, distribuição uniforme da luz e aporte máximo da luz difusa e da reflexão da radiação infravermelha, tanto evitando o excesso da temperatura como economizando energia (NEVES et al., 2016). E também, porque a tela vermelha transfere mais luz do espectro nas ondas vermelho e vermelho distante e difundem a luz que passa através da malha, favorecendo o desenvolvimento da planta, tanto em altura como em diâmetro (LI, 2006).

Os ambientes de produção avaliados não influenciaram no número de perfilhos e de maços. O tipo de colheita utilizado pode ter influenciado nos resultados conforme observaram Simões et al. (2016) e Souza et al. (2015) que concluíram que a colheita na forma de corte raso proporciona maior número de maços e maior produtividade quando comparada a colheita de folhas individuais. Contudo, a maior altura e diâmetro dos perfilhos proporcionados nos ambientes com tela vermelha e tela termo refletora pode ser um atrativo para o consumidor no momento da comercialização (FILGUEIRA, 2013).

Para a variável massa fresca, os tratamentos com tela vermelha e tela termo refletora se diferiram dos demais ambientes, sendo que a tela vermelha apresentou massa fresca $41,78 \%$ maior que o cultivo em pleno sol. Esse resultado, provavelmente está relacionado com a maior altura e diâmetro do perfilho central, também encontrado nestes ambientes. Podendo ser explicado também, pelo efeito da radiação mais intensa no ambiente com tela de sombreamento preta e em pleno sol, promovendo alterações na morfologia da planta, como a altura e o diâmetro (LARCHER, 2006).

Os ambientes com tela vermelha e tela termo refletora também se sobressaíram aos demais para o parâmetro massa seca, com diferença de $34,42 \%$. Hirata et al. (2017), encontraram maiores valores de massa seca de cebolinha cultivada em pleno sol, quando comparado com ambientes protegidos, justificando esses resultados devido ao maior teor de água nas plantas cultivadas sob telas. 
O maior valor de massa seca encontrado nos ambientes com tela vermelha e tela termo refletora pode ser explicado devido ao fato de que no cultivo em pleno sol as folhas apresentam menos clorofila por centro de reação, resultando em menor concentração de fotoassimilados (TAIZ; ZEIGER, 2013).

De forma geral, pode-se inferir que o uso de telas de sombreamento vermelha e termo refletora proporcionam melhores resultados no cultivo de cebolinha e outras hortaliças como alface americana (NEVES et al., 2016), agrião d'água (HIRATA; HIRATA, 2015) e pimenteiras (COSTA et al., 2017), porém este efeito não foi observado por Ricardo et al. (2014) que concluíram que maiores produtividades de alface foram obtidas em cultivo em pleno sol e por Hachmann et al. (2017) que obtiveram maior produtividade de chicória da catalogna em pleno sol.

\section{CONCLUSÔES}

Indica-se o uso de tela vermelha ou termo refletora para a produção de cebolinha (Allium fistulosum L.) na região Cáceres-MT.

\section{REFERÊNCIAS}

ALVES, J.A.; VILAS BOAS, E.V.B.; VILAS BOAS, B.M.; SOUZA, E.D. Qualidade de produto minimamente processado à base de abóbora, cenoura, chuchu e mandioquinha-salsa. Ciência e Tecnologia de Alimentos, Campinas, v.30, n.3, p. 625-634, 2010. Disponível em: http://www.scielo.br/scielo.php?pid=S010120612010000300009\&script=sci_abstract DOI: 10.1590/S0101-20612010000300009

COSTA, E.; SANTO, T.L.E.; BATISTA, T.B.; CURI, T.M.R.C. Diferentes tipos de ambiente protegido e substratos na produção de pimenteiras. Horticultura Brasileira, Vitoria da Conquista, v. 35, n. 3, p. 458-466, 2017. Disponível em $<$ http://www.scielo.br/scielo.php?script=sci_arttext\&pid=S0102-

05362017000300458\&lng=pt\&nrm=iso>.DÖ: $\quad$ http://dx.doi.org/10.1590/s0102053620170324

FILGUEIRA, F.A.R. Novo manual de olericultura: Agrotecnologia moderna na produção e comercialização de hortaliças. 3르 ed. Viçosa, MG: UFV, 2013. 421 p.

FREDDO, A.R.; CECHIM, F.E.; MAZARO, S.M. Conservation of post-harvest leaves of green onion (Allium fistulosum L.) with the use of salicylic acid solution. Brazilian Journal of Applied Technology for Agricultural Science, Guarapuava Paraná, v. 6, n. 3, p.87-94, 2014. DOI: 10.5935/PAeT.V6.N3.10

HACHMANN, T.L.; DALASTRA, G.M.; ECHER, M.M. Características produtivas da chicória da catalogna, cultivada em diferentes espaçamentos sob telas de sombreamento. Caderno de Ciências Agrárias, v. 9, n. 2, p. 48-55, 2017. Disponível em: https://www.researchgate.net/publication/320944215 Caracteristicas produtivas da _chicoria_da_catalogna_cultivada_em_diferentes_espacamentos_sob_telas_de_so mbreamento

HIRATA, A.C.S.; HIRATA, E.K.; MONQUERO, P.A. Manejos do solo associados a telas de sombreamento no cultivo da cebolinha no verão. Horticultura Brasileira, v35, n.2, 2017. Disponível em: http://www.scielo.br/scielo.php?pid=S0102- 
05362017000200298\&script=sci_abstract\&tlng=pt DOI: http://dx.doi.org/10.1590/ S0102-053620170223

HIRATA, A.C.S.; HIRATA, E.K. Desempenho produtivo do agrião d'água cultivado em solo sob telas de sombreamento. Pesquisa Agropecuária Brasileira, Brasília, v.50, n.10, p.895-901, 2015. Disponível em: http://www.scielo.br/pdf/pab/v50n10/1678-3921-pab-50-10-00895.pdf DOI: 10.1590/S0100-204X2015001000005

INMET - Instituto Nacional de Meteorologia. 2017. Consulta dados da estação automática: Cáceres $\quad$ (MT). Disponível em http://www.inmet.gov.br/portal/index.php?r=home/page\&page=rede_estacoes_auto_ graf.LARCHER, W. Ecofisiologia Vegetal. São Carlos: Rima. 532p. 2006.

LI, J.C. Uso de mallas en invernaderos. Revista Extra. Peru. p.86-91. 2006. Disponível em: http://www.horticom.com/revistasonline/revistas/viveros06/jc_li.pdf.

LUZ, J.M.; ANDRADE, L.V.; DIAS, F.F.; SILVA, M.A.; HABER, L.L.; OLIVEIRA, R.C. Produção hidropônica de coentro e salsa crespa sob concentrações de solução nutritiva e posições das plantas nos perfis hidropônicos. Biosciense Journal, v.28, n.4, p. $\quad 589-597, \quad 2012 . \quad$ Disponível em: http://www.seer.ufu.br/index.php/biosciencejournal/article/view/12544

MAKISHIMA, N. O cultivo de hortaliças. Brasília: EMBRAPA-CNPH: EMBRAPASPI, 116p. 1993. Disponível em: https://www.embrapa.br/busca-de-publicacoes//publicacao/749966/o-cultivo-de-hortalicas

NEVES, S.M.A. da S.; NUNES, M.C. M.; NEVES, R.J. Caracterização das condições climáticas de Cáceres/MT Brasil, no período de 1971 a 2009: subsídio às atividades agropecuárias e turísticas municipais. Boletim Goiano de Geografia, Goiânia, v. 31, n. 2, p. 55-68. 2011. DOI 10.5216/bgg.V31i2.16845.

NEVES, J.F.; NODARI, I.D.E.; SEABRA JR.S.; DIAS, L.D.E.; SILVA, L.B.; DALLACORT, R. Produção de cultivares de alface americana sob diferentes ambientes em condições tropicais. Revista Agro@mbiente On-line, v. 10, n. 2, p. 130 - 136, 2016. Disponível em: https://revista.ufrr.br/agroambiente/article/view/3200 DOI:10.18227/1982-8470ragro.v10i2.3200

OLIVEIRA, F.L.; SHALDERS, G.; SOUZA, A.M.; QUARESMA, M.A.L; SILVA, D.M.N.; ZINGER, F.D. Produção de cebolinha a partir de diferentes preparos de mudas. Horticultura Brasileira, v. 30, n. 2, (Suplemento), p. 3853-3860. 2012. Disponível

em: http://www.abhorticultura.com.br/EventosX/Trabalhos/EV_6/A5219_T7323_Comp.pd f

GINEGAR POLYSACK. Aluminet malhas termorefletoras. 2017. Disponível em http://www.ginegarpolysack.com.br/produto\&cod=1\&nomTitulo=Malhas+Termorreflet +Aluminet\%C2\%AE\&it=P 
QUEIROZ, J.P.S; COSTA, A.J.M; NEVES, L.G; SEABRA JUNIOR, S; BARELLI, M.A.A. Estabilidade fenotípica de alfaces em diferentes épocas e ambientes de cultivo. Revista Ciência Agronômica, v. 45, n. 2, p. 276-283, 2014. Disponível em: http://ccarevista.ufc.br/seer/index.php/ccarevista/article/view/1913.

RICARDO, A.S.; VARGAS, P.F. FERRARI, S.; PAVARINI, G.M.P. Telas de sombreamento no desempenho de cultivares de alface. Nucleus, v.11, n.2, 2014. Disponível em: http://www.nucleus.feituverava.com.br/index.php/nucleus/article/view/ 1375. DOI: $10.3738 / 1982.2278 .1375$

SABINO, M.; KORPAN, C.; FERNEDA, B.G.; SILVA, A.V. Crescimento de mudas de ipê em diferentes telas de sombreamento. Nativa. Sinop, v. 4, n.2, p.61-65. 2016. DOI: 10.14583/2318-7670.v04n02a01.SANTOS, C.L.; SEABRA JÚNIOR, S.; NUNES, M.C.M. Luminosidade, temperatura do ar e do solo em ambientes de cultivo protegido. Revista de Ciências Agro-Ambientais, Alta Floresta, v.8, n.1, p.83- 93, 2010. Disponível em: http://www.unemat.br/revistas/rcaa/docs/vol8/8_artigo_v8.pdf

SILVA, A. P. G.; BORGES, C. D.; MIGUEL, A. C. A.; JACOMINO, A.P.; MENDONÇA, C. R. B. Características físico-químicas de cebolinhas comum e europeia. Brazilian Journal of Food Technology, Campinas, v. 18, n. 4, p. 293298, 2015. Disponível em: http://www.scielo.br/scielo.php?pid=S1981$67232015000400293 \&$ script $=$ sci_abstract\&tlng $=$ pt http://dx.doi.org/10.1590/1981-67̄23.3015

SILVA, F. de A.S.; AZEVEDO, C.A.V. de.The Assistat Software Version 7.7 and its use in the analysis of experimental data. African Journal of Agricultural Research v.11, p.3733-3740. 2016. Disponível em: https://academicjournals.org/journal/AJAR/article-full-text-pdf/5E8596460818. DOI: 10.5897/AJAR2016.11522.

SIMÕES, A. C.; ALVES, G. K. E. B; SILVA, N.M.; FERREIRA, R.L.F.; NETO, S.E.A. Densidade de plantio e método de colheita de cebolinha orgânica. Agropecuária Científica no Semiárido, v.12, n.1, p.93-99, 2016. Disponível em: http://revistas.ufcg.edu.br/acsa/index.php/ACSA/article/view/744/pdf DOI: http://dx.doi.org/10.30969/acsa.v12i1.744

SOUZA, B.P.; SIMÕES, A.C.; ALVES, G.K.E.B; FERREIRA, R.L.F.; NETO, S.E.A. Produtividade e rentabilidade de cebolinha orgânica sob diferentes densidades de plantio e métodos de colheita. Enciclopédia Biosfera, Centro Científico Conhecer Goiânia, v.11 n.21; $\quad$ p. 1576-1585, 2015. Disponível em http://www.conhecer.org.br/enciclop/2015b/agrarias/Produtividade\%20e\%20rentabili dade.pdf

TAIZ L; ZEIGER E. Fisiologia vegetal. 5르 ed. Porto Alegre: Artmed, 954 p. 2013. 